\title{
Surface functionalized magnetic nanoparticles for separation of beta-blocker Propranolol from aqueous solution
}

\author{
Sudipa Ghosh*' ${ }^{1}$, Quek Jee Teck ${ }^{1}$, M. S. Uddin ${ }^{2}$, K. Hidajat ${ }^{1}$ \\ ${ }^{1}$ Department of Chemical and Biomolecular Engineering \\ National University of Singapore Engineering Drive 4, Singapore 117576 \\ ${ }^{2}$ Department of Biotechnology Engineering \\ International Islamic University Malaysia \\ P.O. Box 10, 50728 Kualalumpur \\ E-mail:sudipa047@yahoo.com
}

Abstract: The present study investigates adsorption separation of beta-blocker ( $\beta$-blocker), propranolol utilizing surface functionalized magnetic nanoparticles (MNPs) from phosphate buffer solution. Surface of MNP is functionalized with silica and carboxymethyl- $\beta$-cyclodextrin (CMCD) to scrutinize sorption removal characteristics. Modified MNPs are characterized by Fourier Transform Infrared (FTIR) Spectroscopy, Transmission Electron Microscopy (TEM) etc. Adsorption of propranolol onto magnetic nanoadsorbents is found to be dependent on solution $\mathrm{pH}$ and adsorption capacity of adsorbent increases as $\mathrm{pH}$ increases from 3 to 9 and then reaches plateau at $\mathrm{pH} 11$. It appears that modified hydrophobicity of beta-blocker, propranolol affects interaction with cyclodextrin functionalized magnetic nanoparticles as well as adsorption capacity of the pollutant. Equilibrium data in aqueous solution is well represented by Freundlich isotherm model. XPS analysis reveals that propranolol adsorption on magnetic nanoparticles involves nitrogen atoms in side chain of propranolol to form surface complexes. Finally, desorption studies are carried out in different concentration of methanol solution and $50 \%$ methanol solution was found to be effective for almost complete desorption.

\section{INTRODUCTION}

In the recent decades, pharmaceutical compounds received immense concern as emerging micropollutants for the contamination of aquatic environments [1]. Among the pharmaceuticals, beta-blockers (sometimes written as $\beta$-blockers) or beta-adrenergic blocking agents constitute a class of drugs used for various indications. As beta adrenergic receptor antagonists, they are widely used to treat a variety of cardiovascular diseases by diminishing the effects of epinephrine (adrenaline) and other stress hormones on the $\beta$-adrenergic receptor in the body, primarily in heart [2]. Propranolol, a $\beta$-adrenergic blocking agent, is widely used in the treatment of cardiovascular diseases (hypertension, cardiac arrhythmia). Propranolol is available in generic form as propranolol hydrochloride; some of the properties of propranolol hydrochloride are presented in Table 1. It is considered to be of low volatility, highly persistent $[3,4]$, and bioaccumulative [5]. Moreover, it was found that propranolol had the highest acute and chronic toxicity within the class of the $\beta$-blockers [6]. So development of more effective technologies to remove propranolol from aqueous environment is of prime importance.

Among the other methods, photo degradation has been utilized by many researchers as a way of removal of $\beta$ blockers from aqueous solution [7]. But photo degradation is accompanied by many disadvantages such as high energy consumption, generation of secondary products, complicated reaction pathways. Compared to other methods, adsorption has become one of the most promising techniques for removal of pharmaceuticals from aqueous solution, due to its convenience, less/ no energy consumption, efficacy etc. Recently, many studies have focused on use of superparamagnetic nanoparticles as alternative adsorbents for sorption separation/ removal of organic and inorganic contaminants [8, 9] etc. These superparamagnetic materials possess an advantage that they do not retain any magnetization after removal of external magnetic field. In addition, it is desired that the magnetic nanoparticles remain nonaggregated and are stable against oxidation from the point of these technological and medical applications. If considered as surface modifying agent, silica particles are not toxic and are also highly biocompatible. They are regularly used as food additives and components of vitamin supplements. In addition, amorphous silica particles have surfaces decorated with hydroxyl groups which not only render them intrinsically hydrophilic but also provide platform for further surface functionalization. On the other hand, cyclodextrins (CDs) are torus shaped cyclic oligosaccharides consisting of $\alpha-(1,4)$ linked glucose units. A characteristic feature of cyclodextrin is the presence of an internal hydrophobic cavity with a remarkable capacity to form inclusion complexes [11]. Studies have been reported for adsorption of $\beta$-blocker propranolol onto other adsorbent such as modified attapulgites [12], cyclodextrin polymer [13]. However to the best of our knowledge, reports about silica and cyclodextrin coated magnetic nanoparticles used in separation of $\beta$-blocker are rather limited. 
The primary objectives of this study were to investigate the sorption behavior of propranolol onto silica and cyclodextrin derivative-carboxymethyl- $\beta$-cyclodextrin modified magnetic nanoparticles to evaluate their feasibility for removing propranolol from aqueous solution in ppm concentrations.

Table 1. Physicochemical properties of propranolol.

\begin{tabular}{|c|c|c|c|c|c|c|}
\hline Compound & Molecular structure & $\begin{array}{l}\mathrm{MW} \\
(\mathrm{g} / \mathrm{mol})\end{array}$ & $\begin{array}{l}\log K_{\mathrm{o}} \\
\mathrm{w}\end{array}$ & $\mathrm{p} K_{\mathrm{a}}$ & $\begin{array}{l}\log D \text { at } \\
\mathrm{pH} 3,7 \\
\text { and } 9\end{array}$ & $\begin{array}{l}\text { Water } \\
\text { solubility } \\
(\mathrm{mg} / \mathrm{L} \text { at } \\
\left.25^{\circ} \mathrm{C}\right)\end{array}$ \\
\hline $\begin{array}{l}\text { Propranolol } \\
\text { hydrochloride }\end{array}$ & & 295.8 & $3.48^{\mathrm{a}}$ & $9.42^{\mathrm{a}}$ & $\begin{array}{c}-2.94^{\mathrm{a}} \\
1.06^{\mathrm{a}} \\
2.92^{\mathrm{a}}\end{array}$ & 150 \\
\hline
\end{tabular}

\section{Materials and Methods}

\subsection{Reagents and samples}

The following chemicals were used in this study: Iron (II) chloride tetrahydrate (98\%) (Alfa Aesar), iron (III) chloride hexahydrate (98\%) (Alfa Aesar), citric acid (99\%) (Alfa Aesar), cyanamide (98\%) (Alfa Aesar), ammonium hydroxide (25\%) (Merck), propranolol hydrochloride $(99 \%)$ (Sigma-Aldrich), tetraethyl orthosilicate (TEOS) (99\%) (Fluka), $\beta$-cyclodextrin hydrate (99\%) (Sinopharm Chemical). 2-propanol (99.9\%) (Fisher Scientific) and acetone (99.5\%) (Merck), methanol (99.5\%) (Merck) were distilled before use. All the chemicals were of analytical grade and were used as received without further treatment.

\subsection{Methods}

\subsubsection{Synthesis of bare and coated magnetic} nanoparticles: Nanosized bare magnetic particles were synthesized by chemical co-precipitation method and the procedure of silica coating follows a modified stöber method as mentioned in our previous work [15]. A solution of the magnetic nanoparticles was prepared by mixing $1 \mathrm{~g}$ dry bare MNPs in $200 \mathrm{~mL}(0.3 \mathrm{M})$ of citric acid and the resulting solution was sonicated for $1 \mathrm{hr}$ followed by mechanical stirring for $12 \mathrm{hrs}$ at $400 \mathrm{rpm}$ at room temperature. Citric acid modified nanoparticles (CMPs) were washed several times with distilled water, isolated with help of a magnet and dried at $60{ }^{\circ} \mathrm{C}$ in vacuum for 2 hrs.
Subsequently, $1 \mathrm{~g}$ of CMP was mixed with $40 \mathrm{~mL}$ deionized (DI) water and $200 \mathrm{~mL}$ of 2-propanol and sonication for 15 mins was carried out to maintain proper dispersion. Under continuous mechanical stirring, $20 \mathrm{~mL}$ of ammonia solution (25\%) and $1.5 \mathrm{~mL}$ tetraethyl orthosilicate (TEOS) were added. The reaction was allowed to proceed at room temperature at $650 \mathrm{rpm}$ for 6 hrs. The silica coated core shell magnetic nanoparticles $\left(\mathrm{Fe}_{3} \mathrm{O}_{4} / \mathrm{SiO}_{2}\right.$ MNPs $)$ were isolated by magnetic decantation to remove the unbound silica particles and at vacuum after being washed with de-ionized water, 2propanol and acetone.

A derivative of $\beta$-cyclodextrin, carboxymethyl- $\beta$ cyclodextrin was synthesized according to the method proposed in our previous work [15]. $1 \mathrm{~g}$ of dry $\mathrm{Fe}_{3} \mathrm{O}_{4} / \mathrm{SiO}_{2}$ MNPs were mixed with $20 \mathrm{~mL}$ of sodium phosphate buffer $(0.03 \mathrm{M}, \mathrm{pH} 6)$ and sonicated for 15 mins. Then $125 \mathrm{mg}$ of cyanamide was dissolved separately in $5 \mathrm{~mL}$ of the same buffer solution and added to the previous mixture. Further sonication was done for 15 mins and finally $25 \mathrm{~mL}$ of CMCD solution (50 $\mathrm{mg} / \mathrm{mL}$ in same buffer solution) was added and the reaction was continued for $2 \mathrm{hrs}$. The final product of CMCD coated magnetic silica nanoparticles $\left(\mathrm{Fe}_{3} \mathrm{O}_{4} / \mathrm{SiO}_{2} / \mathrm{CMCD} \mathrm{MNPs}\right)$ were washed several times with sodium phosphate buffer. 


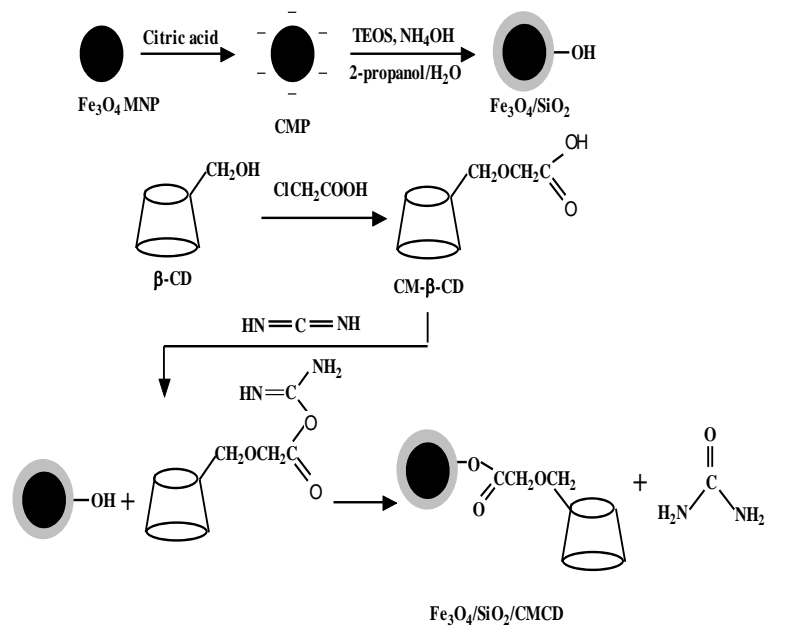

Fig. 1: Scheme representation of silica and CMCD

coating on bare magnetic nanoparticles.

2.2.2 Characterization of magnetic nanoparticles: A Field Emission TEM (JEOL 2011F) (at an acceleration voltage of $200 \mathrm{kV}$ ) was used to determine size and morphology of the magnetic nanoparticles. The TEM samples were prepared by coating a copper grid (200 mesh and cover with formvar/ carbon) with a thin layer of diluted particle suspension. The copper grid was then dried at room temperature for $24 \mathrm{hrs}$ before the measurement. The Shimadzu infrared spectrometer (Model No. 8400) was used to characterize all the synthesized particles at room temperature using $\mathrm{KBr}$ pellets over a broad wavelength ranging from 400 to $4000 \mathrm{~cm}^{-1}$. XPS measurements were made on an Axis Ultra DLD (Kratos) spectrometer with $\mathrm{Al}$ mono $\mathrm{K} \alpha \mathrm{X}$ ray source (1486.71 eV photons) at a constant retard ratio of 40 . The sample was mounted on the standard sample studs by means of double sided adhesive tape. The core-level signals were obtained at a photoelectron take-off angle $90^{\circ}$ (with respect to the sample surface). The X-ray source was run at a reduced power of $75 \mathrm{~W}$. The pressure in the analysis chamber was maintained at $2 \times 10^{-8}$ Torr or lower during each measurement.

2.2.3 Adsorption and desorption experiments: Effect of $\mathrm{pH}$ on adsorption of propranolol was examined over the $\mathrm{pH}$ range from 3-11 at initial concentration of 50 $\mathrm{ppm}$. Three buffer systems, i.e., $0.01 \mathrm{M}$ sodium acetic

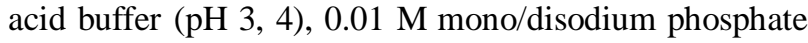
buffer $(\mathrm{pH} 6,7)$, and $0.01 \mathrm{M}$ tris- $\mathrm{HCl}$ buffer $(8,9,11)$, were used for the experiments. Adsorption of betablocker, propranolol hydrochloride was investigated using a batch equilibrium mode by adding $60 \mathrm{mg}$ of wet $\mathrm{Fe}_{3} \mathrm{O}_{4} / \mathrm{SiO}_{2} / \mathrm{CMCD}$ MNPs into $4 \mathrm{~mL}$ of propranolol hydrochloride solutions with different concentrations $(10-50 \mathrm{ppm})$. Samples for equilibrium adsorption studies were prepared in de-ionized water. Solution $\mathrm{pH}$ was adjusted by adding $0.01 \mathrm{M} \mathrm{NaOH}$ or $0.01 \mathrm{M} \mathrm{HCl}$.

After preparation of propranolol solution, samples were stirred by a horizontal laboratory shaker at $230 \mathrm{rpm}$ and after the equilibrium was reached, MNPs were removed by magnetic decantation from the solution before measurements. Some initial kinetic studies were done and it showed that adsorption reached equilibrium within $1 \mathrm{hr}$. Residual concentrations of propranolol hydrochloride in solutions were determined by Shimadzu UV-visible spectrophotometer (Model 1800) and absorbance values were recorded at $289 \mathrm{~nm}$. The amounts of solute adsorbed per unit mass of adsorbent were calculated from the differences between initial and the final solute concentrations in solution before and after adsorption following equation 1.

$$
Q_{e}=\frac{\left(C_{i}-C_{e}\right) \times V}{w}
$$

where $Q_{e}(\mathrm{mg} / \mathrm{g})$ is the adsorption capacity of the sorbent, $V(\mathrm{~mL})$ is the volume, $C_{i}$ and $C_{e}(\mathrm{mg} / \mathrm{mL})$ are the initial and final solution concentration of propranolol hydrochloride and $w(\mathrm{mg})$ is the dry mass of the solid.

Desorption studies of beta-blocker, propranolol was carried out using three different composition of alcohol solution, $10 \%$ methanol solution, $30 \%$ methanol solution and $50 \%$ solution when adsorption was carried out at $\mathrm{pH}$ 7 (sodium phosphate buffer solution). After equilibrium was achieved for adsorption, supernatant was separated from magnetic particles by the help of a magnet. Then particles were washed using Mili Q water. Magnetic particles containing propranolol was then mixed with $5 \mathrm{~mL}$ alcohol solution. After $1 \mathrm{hr}$ incubation at $25^{\circ} \mathrm{C}$, supernatant was collected and analysed with UV spectrometer at $289 \mathrm{~nm}$. 


\section{Results and Discussion}

\subsection{Characterization by FTIR spectroscopy}

The FTIR spectra of bare MNPs, CMPs and $\mathrm{Fe}_{3} \mathrm{O}_{4} / \mathrm{SiO}_{2} / \mathrm{CMCD}$ MNPs are presented in Fig. 2. When compared, it can be inferred that the existence of the characteristic $\mathrm{Si}-\mathrm{O}-\mathrm{Si}$ stretching at $1088 \mathrm{~cm}^{-1}$ on $\mathrm{Fe}_{3} \mathrm{O}_{4} / \mathrm{SiO}_{2} / \mathrm{CMCD} \mathrm{MNPs}$ are evidences to confirm the formation of the silica shell [10, 16].On $\mathrm{Fe}_{3} \mathrm{O}_{4} / \mathrm{SiO}_{2} / \mathrm{CMCD}$ MNPs, other characteristic absorption bands such as $\mathrm{Si}-\mathrm{OH}$ stretching, $\mathrm{Si}-\mathrm{O}$ bending and $\mathrm{Si}-\mathrm{O}-\mathrm{Si}$ bending, are shown at 958, 794, and $459 \mathrm{~cm}^{-1}$, respectively [17]. Characteristic $\mathrm{Fe}-\mathrm{O}$ peak of bare MNPs at $586 \mathrm{~cm}^{-1}$ is shifted to $584 \mathrm{~cm}^{-1}$ and $576 \mathrm{~cm}^{-1}$ in the spectrum of CMPs and $\mathrm{Fe}_{3} \mathrm{O}_{4} / \mathrm{SiO}_{2} / \mathrm{CMCD}$ MNPs, respectively. Thus, undoubtedly it can be said that the silica shell is linked to the surface of the magnetic nanoparticles by $\mathrm{Fe}-\mathrm{O}-\mathrm{Si}$ chemical bond. The most important asymmetric and symmetric $\mathrm{C}-\mathrm{H}$ stretching bands are found at 2855 and $2924 \mathrm{~cm}^{-1}$ respectively, which prove successful grafting of CMCD on silica coated magnetic particles [10].



Fig. 2: FTIR spectra of (a) bare MNPs, (b) CMPs, (c) $\mathrm{Fe}_{3} \mathrm{O}_{4} / \mathrm{SiO}_{2} / \mathrm{CMCD}$ MNPs.

\subsection{TEM images}

TEM images of bare MNPs, CMPs and $\mathrm{Fe}_{3} \mathrm{O}_{4} / \mathrm{SiO}_{2} / \mathrm{CMCD}$ MNPs are presented in Fig. 3. From Fig. 3(a) and Fig. 3(b). It is clear that the synthesized bare nanoparticles and CMPs are well dispersed, but also in some areas aggregates of larger particles are observed. Fig. 3(c) depicts the TEM image of $\mathrm{Fe}_{3} \mathrm{O}_{4} / \mathrm{SiO}_{2} / \mathrm{CMCD}$ MNPs. Images of bare and coated MNPs were taken using HRTEM (High Resolution Transmission Electron Microscope) machine and afterwards, size of at least 100 particles from different areas were measured and average size of the particles were calculated using equation 2:

$$
d_{i}^{\prime}=\frac{\sum\left(d_{i} \times n_{i}\right)}{\sum n_{i}}
$$

where, $n_{i}=$ No. of Particles within the same size range, $d_{i}=$ Particle diameter of the same size range, $d_{i}{ }^{\prime}=$ Average particle size. The average size of bare nanoparticles and CMPs are about $11 \mathrm{~nm}$ and $12 \mathrm{~nm}$, respectively. It can be clearly seen that the samples are nearly all in core-shell structures and average diameter of the $\mathrm{Fe}_{3} \mathrm{O}_{4} / \mathrm{SiO}_{2} / \mathrm{CMCD}$ MNPs is around $30 \mathrm{~nm}$.

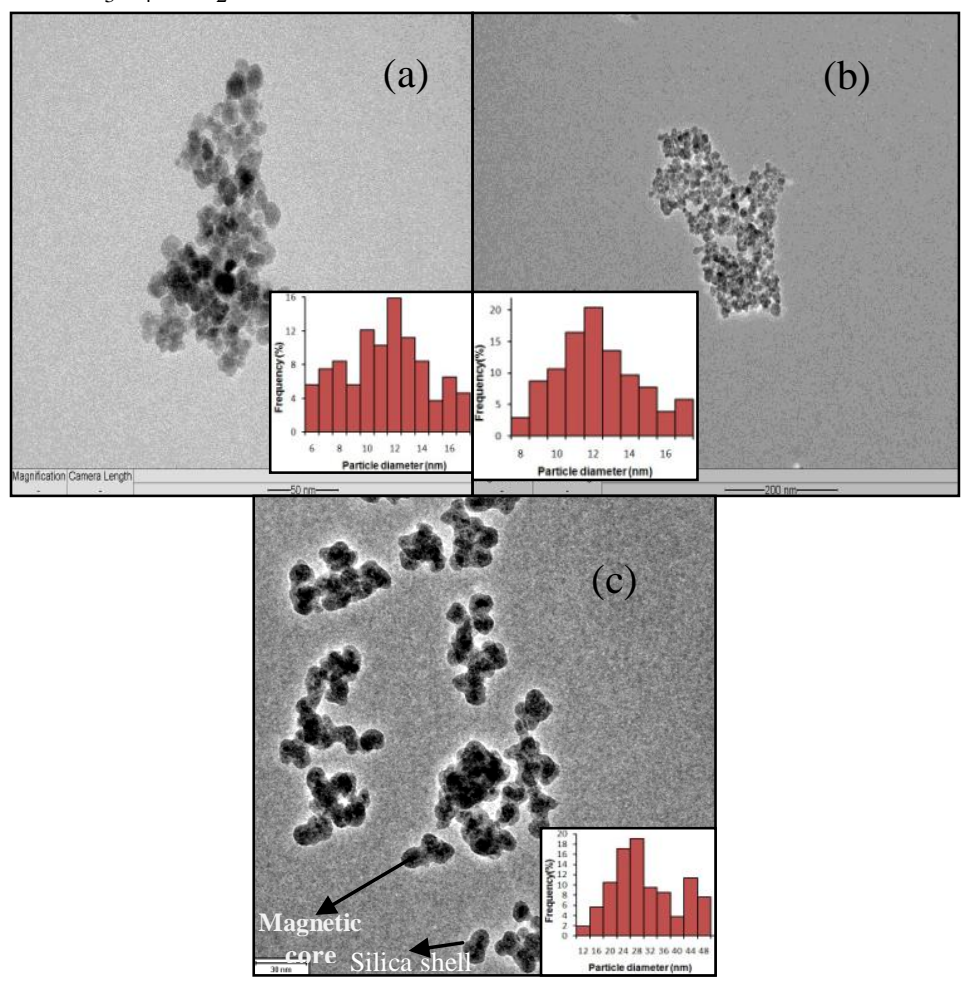

Fig. 3: TEM images of (a) bare MNPs (scale bar is 50 $\mathrm{nm}$ ), (b) CMPs (scale bar is $200 \mathrm{~nm}$ ), (c) $\mathrm{Fe}_{3} \mathrm{O}_{4} / \mathrm{SiO}_{2} / \mathrm{CMCD}$ MNPs (scale bar is $30 \mathrm{~nm}$ ).

\subsection{Adsorption of propranolol}

3.3.1 Effect of initial pH: The sorption of propranolol onto $\mathrm{Fe}_{3} \mathrm{O}_{4} / \mathrm{SiO}_{2} / \mathrm{CMCD}$ MNPs as a function of initial solution $\mathrm{pH}$ was also investigated in the $\mathrm{pH}$ range of $3-$ 11 (Fig. 4). As can be seen in Fig. 4, adsorption capacities of nanoadsorbents toward propranolol increase with increase in $\mathrm{pH}$. 


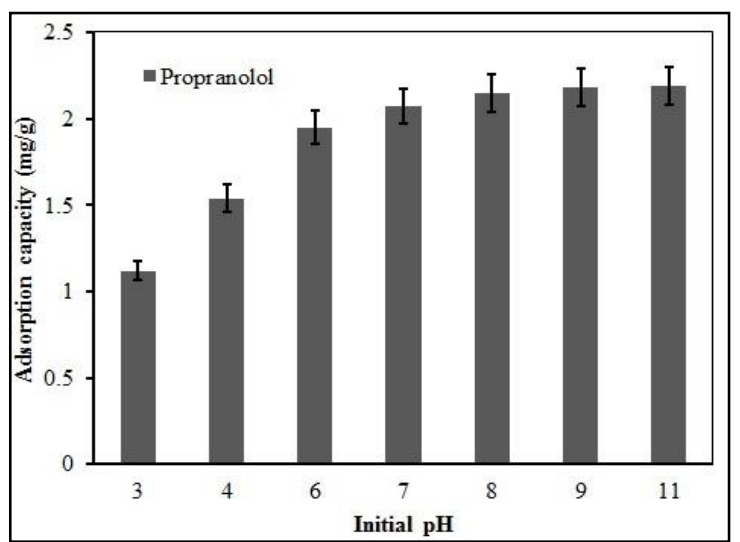

Fig.4: Effect of $\mathrm{pH}$ on adsorption of propranolol on the sorbents $\left(\mathrm{T}=25^{\circ} \mathrm{C}, \mathrm{C}_{\mathrm{i}}=50 \mathrm{ppm}\right.$, sorbent dosage $=60 \mathrm{mg} / 4 \mathrm{~mL}$ ).

In the case of propranolol $\left(\mathrm{p} K_{\mathrm{a}}=9.42\right)$, it exists as a neutral compound in the tested $\mathrm{pH}$ below its $\mathrm{pKa}$ and it exists as negatively charged molecule above its $\mathrm{pKa}$ [12]. Species distribution of propranolol has been depicted in Fig 5. Thus, adsorption of propranolol onto $\mathrm{Fe}_{3} \mathrm{O}_{4} / \mathrm{SiO}_{2} / \mathrm{CMCD}$ MNPs can be controlled by both nonelectrostatic and electrostatic interaction. In the prepared sample, propranolol was present in either neutral or ionized forms, depending upon the solution $\mathrm{pH}$. It was reported that interaction forces between propranolol and cyclodextrin molecules are hydrogen bonding and hydrophobic interaction [13]. Adsorption capacity of the nano-adsorbent bearing cyclodextrin moieties toward $\beta$ blocker, propranolol is based on two factors, namely, the hydrophobicity of the drug (conditioned by the value of the octanol water partition coefficient, $\left.K_{\text {ow }}\right)$ and ionization of the molecule (determined by the values of $\mathrm{pH}$ and $\mathrm{p} K_{\mathrm{a}}$ ). Both parameters $K_{\mathrm{ow}}$ and $\mathrm{p} K_{\mathrm{a}}$ can be taken into account for calculation of $\log D . \log D$ is a $\mathrm{pH}$ dependent modified octanol water partition coefficient and is relevant for solutes that are partly dissociated or protonated [18]. It can be calculated using following equations 3 and 4. For acidic molecules $\log D$ is determined as:

$$
\log D=\log K_{\text {ow }}-\log \left(1+10^{(p H-p K a)}\right)
$$

Whereas for basic molecules $\log \mathrm{D}$ is:

$$
\log D=\log K_{\text {ow }}-\log \left(1+10^{(p K a-p H)}\right)_{(4)}
$$

The modified $\log D$ value of propranolol at $\mathrm{pH} 3,7$ and 9 are calculated as $-2.94,1.06,2.92$ [14]. According to the modified hydrophobicity values, hydrophobicity of propranolol increases from $\mathrm{pH} 3$ to $\mathrm{pH} 9$. Noteworthy, the chemical structure of $\mathrm{Fe}_{3} \mathrm{O}_{4} / \mathrm{SiO}_{2} / \mathrm{CMCD}$ MNPs (Fig. 1) suggests that presence of ionizable groups on the

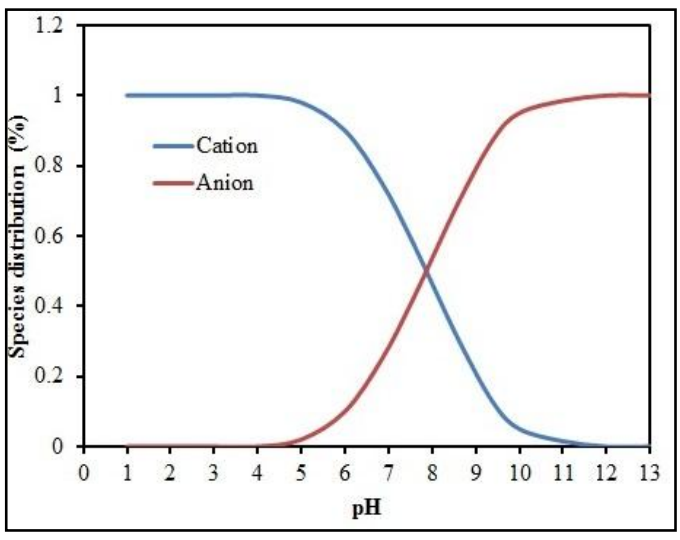

Fig. 5: Species distribution of propranolol.

surface is very limited. Thus, hydrophobic interaction between CMCD and propranolol molecules should be dominating. As a result, higher adsorption capacities of $\mathrm{Fe}_{3} \mathrm{O}_{4} / \mathrm{SiO}_{2} / \mathrm{CMCD} \mathrm{MNPs}$ toward propranolol at higher solution $\mathrm{pH}$ are justified.

3.3.2 Adsorption isotherm: Equilibrium isotherms for adsorption of propranolol in single solute system by both $\mathrm{Fe}_{3} \mathrm{O}_{4} / \mathrm{SiO}_{2} / \mathrm{CMCD}$ MNPs and bare MNPs at $\mathrm{pH} 7$ and $25^{\circ} \mathrm{C}$ are shown in Fig. 6. From the various isotherm equations that are used to analyze adsorption data in aqueous phase, the Langmuir-the theoretical equilibrium isotherm and the Freundlich-the empirical equilibrium isotherm are the most common models. The Langmuir model was originally developed to represent physisorption on a set of well-defined localized adsorption sites having the same adsorption energy, independent of the surface coverage and with no interaction between adsorbed molecules. On the other hand, the Freundlich isotherm, one of the more widely employed mathematical descriptions, usually fits the experimental data over a wide range of concentrations. This isotherm gives an empirical expression encompassing the surface heterogeneity and the exponential distribution of active sites and their energies. The Langmuir equation can be expressed as [19]:

$\frac{C_{e}}{Q_{e}}=\frac{1}{Q_{m} k_{L}}+\frac{C_{e}}{Q_{m}}$

where $Q_{e}$ is the amount of adsorbed material at equilibrium $(\mathrm{mg} / \mathrm{g}), C_{\mathrm{e}}$ the equilibrium concentration in solution $(\mathrm{mg} / \mathrm{mL}), Q_{\mathrm{m}}$ the maximum capacity of adsorbent $(\mathrm{mg} / \mathrm{g})$, and $k_{\mathrm{L}}$ is the "affinity parameter" or Langmuir constant (mL/mg). 
The linear form of Freundlich equation, which is an empirical equation derived to model the heterogenous adsorption, can be represented as follows [20]:

$$
\ln Q_{e}=\ln k_{F}+(1 / n) \ln C_{e}
$$

where $Q_{\mathrm{e}}$ and $C_{\mathrm{e}}$ are defined as above, $k_{\mathrm{F}}$ is Freundlich constant $(\mathrm{mL} / \mathrm{g})$, and $n$ is the heterogeneity factor. As can be seen from Fig. 6 (a), the maximum adsorption capacities of $\mathrm{Fe}_{3} \mathrm{O}_{4} / \mathrm{SiO}_{2} / \mathrm{CMCD}$ MNPs toward propranolol is $2.078 \mathrm{mg} / \mathrm{g}$ at $25^{\circ} \mathrm{C}$ and $\mathrm{pH} 7$, whereas those using bare MNPs is $0.652 \mathrm{mg} / \mathrm{g}$, at the same experimental condition. Thus, $\mathrm{Fe}_{3} \mathrm{O}_{4} / \mathrm{SiO}_{2} / \mathrm{CMCD}$ MNPs could adsorb propranolol more than three times than that by bare magnetic nanoparticles indicating that the modification of magnetite surface with CMCD which has hydrophobic cavity could enhance the adsorption capacities. However, all the experimental data were fitted well to Freundlich isotherm model than Langmuir model $\left(R^{2}>0.99\right)$. Thus, the adsorption process is governed by heterogenous adsorption.

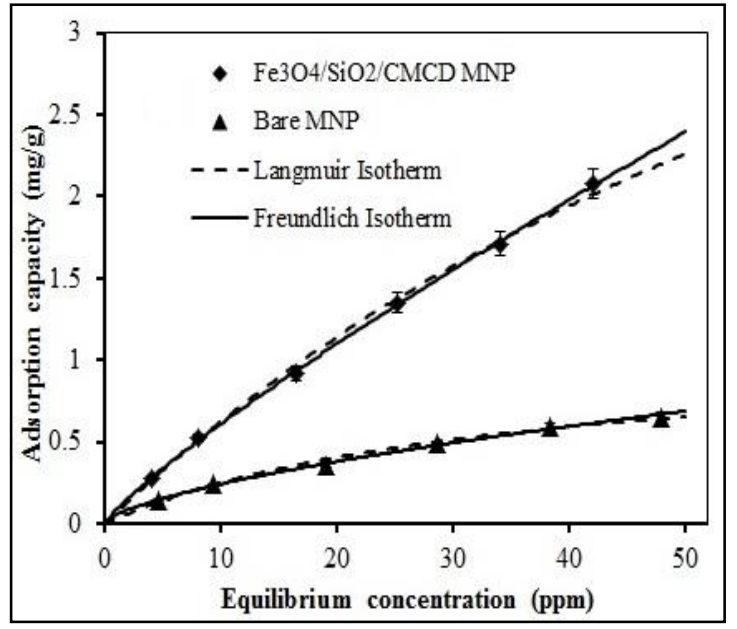

Fig. 6: Sorption isotherm of propranolol onto $\mathrm{Fe}_{3} \mathrm{O}_{4} / \mathrm{SiO}_{2} / \mathrm{CMCD}$ MNPs and bare MNPs .

\subsection{Investigation of Adsorption mechanism with XPS spectroscopy}

To scrutinize adsorption mechanism of propranolol on magnetic nanoparticles, XPS analyses were carried out on propranolol and $\mathrm{Fe}_{3} \mathrm{O}_{4} / \mathrm{SiO}_{2} / \mathrm{CMCD}$ MNPs after adsorption of propranolol and the corresponding results are shown in Table 2. There are major changes in the $\mathrm{N} 1 \mathrm{~s}$ spectra of the propranolol before and after adsorption onto $\mathrm{Fe}_{3} \mathrm{O}_{4} / \mathrm{SiO}_{2} / \mathrm{CMCD}$ MNPs, which indicates that the amino group of propranolol took part in adsorption and complex formation. Clearly, the spectrum of propranolol exhibits two N1s peaks at 398.4 and $400.5 \mathrm{eV}$ which could be attributed due to N-H and $\mathrm{N}-\mathrm{C}$ functional groups. After adsorption of propranolol onto $\mathrm{Fe}_{3} \mathrm{O}_{4} / \mathrm{SiO}_{2} / \mathrm{CMCD}$ MNPs, the spectrum shows peak at $401.2 \mathrm{eV}$ corresponding to the peak at $398.4 \mathrm{eV}$ and peak at $402.3 \mathrm{eV}$ corresponding to the peak at $400.5 \mathrm{eV}$ in native propranolol. However, binding energy (BE) of the peaks shifted to higher $\mathrm{eV}$ after adsorption compared to that of the native propranolol molecule. The significant change in $\mathrm{BE}$ of $\mathrm{N} 1 \mathrm{~s}$ indicates propranolol-magnetic nanoparticle complex formation occurred. Because of the favorability of amide bond formation, free electron density of nitrogen atom is greatly reduced. As a result, the BE of $\mathrm{N}$ 1s increased considerably. Furthermore, O1s spectra of $\mathrm{Fe}_{3} \mathrm{O}_{4} / \mathrm{SiO}_{2} / \mathrm{CMCD}$ MNPs depicts two oxygen peaks at $530.3 \mathrm{eV}$ and $532.8 \mathrm{eV}$ due to presence of $\mathrm{C}=\mathrm{O}$ and $\mathrm{C}-\mathrm{O}-\mathrm{H} / \mathrm{C}-\mathrm{O}-\mathrm{C}$ group, respectively which originates from presence of CMCD on nanoparticles' surface. After adsorption of propranolol on magnetic nanoparticles' surface, binding energy of $\mathrm{C}-\mathrm{O}-\mathrm{H} / \mathrm{C}-\mathrm{O}-\mathrm{C}$ group shifted to higher $\mathrm{eV}$ which represents that interaction with the secondary hydroxyl group of the cyclodextrin outer rim on the magnetic nanoparticles took place (data shown in Table 2). Apart from these, there are no major changes in $\mathrm{C} 1 \mathrm{~s}$ spectra.

Thus, from XPS analysis, it can be surmised that the hydrophobic part of propranolol penetrated into the hydrophobic cavity of CMCD and nitrogen molecule was involved into hydrogen bond formation. Structure of beta cyclodextrin and adsorption mechanism is depicted in Fig. 7. 
Table 2. XPS data analyses for adsorption of propranolol.

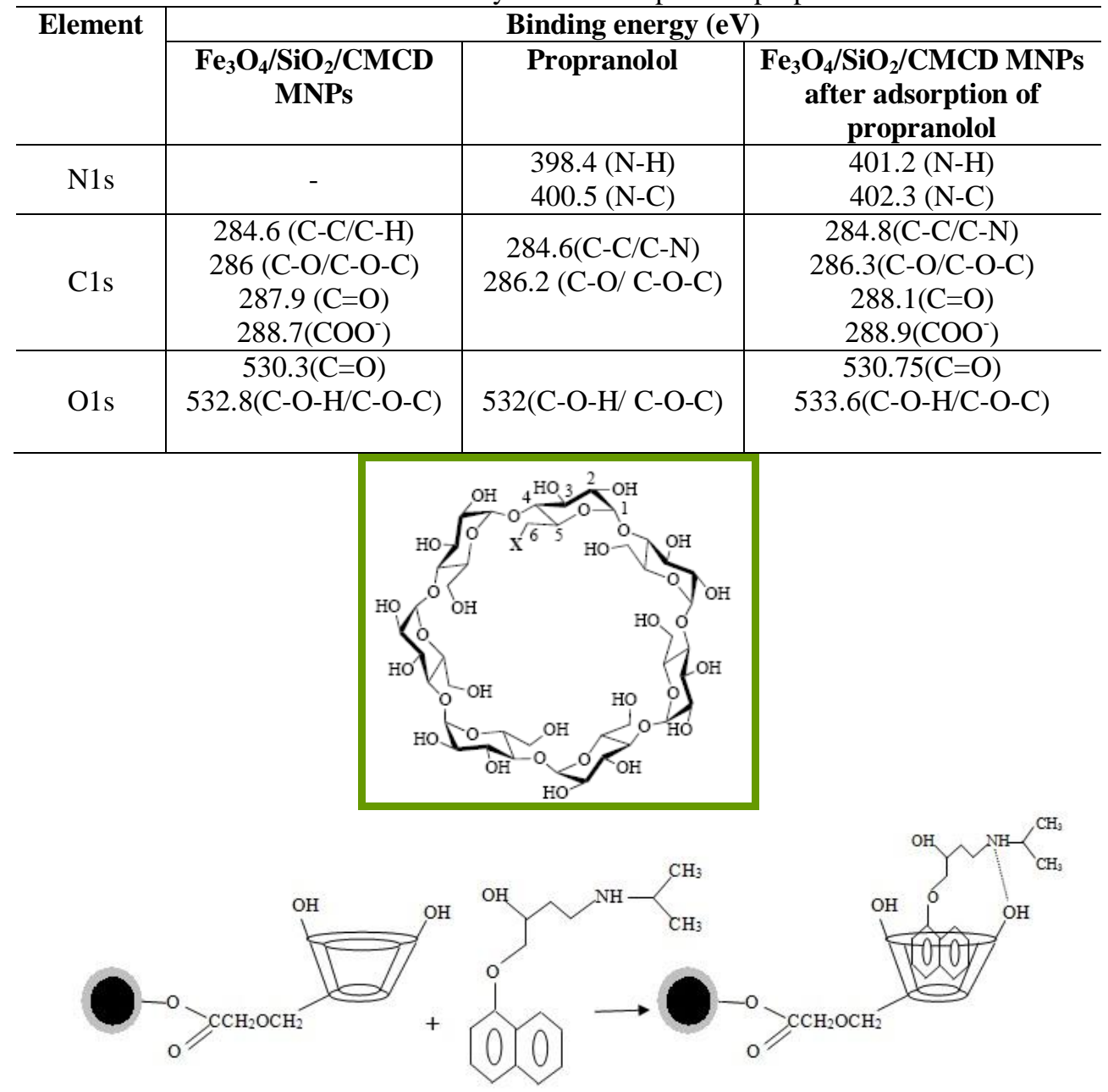

Fig. 7: (a) Structure of beta cyclodextrin, (b) simplified schematic showing adsorption mechanism of propranolol onto $\mathrm{Fe}_{3} \mathrm{O}_{4} / \mathrm{SiO}_{2} / \mathrm{CMCD}$ MNPs.

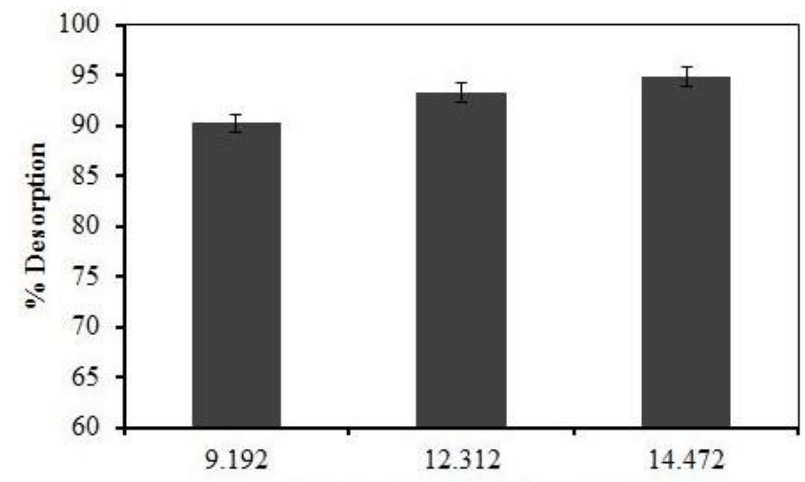

Fig. 8: Desorption of propranolol from $\mathrm{Fe}_{3} \mathrm{O}_{4} / \mathrm{SiO}_{2} / \mathrm{CMCD}$ MNPs as a function of loading of adsorbent. Adsorption condition: propranolol $50 \mathrm{ppm}$; $\mathrm{pH} 7$; temperature $25^{\circ} \mathrm{C}$, contact time $5 \mathrm{hrs}$. Desorption condition $\mathrm{Fe}_{3} \mathrm{O}_{4} / \mathrm{SiO}_{2} / \mathrm{CMCD}$ MNPs; $50 \%$ methanol solution, temperature $25^{\circ} \mathrm{C}$, contact time 6 hrs.

\subsection{Desorption studies}

The success of an adsorption process usually depends on regeneration step of the adsorbent from economic point of view. There are a number of regeneration techniques such as thermal, steam, acid, base, and solvent regenerations. In this study, acetonitrile and methanol and were used as desorbing agents for propranolol. Among these, methanol solution was found as effective desorbing agent. Desorption of propranolol from nanomagnetic particles was carried out separately by $10 \%, 30 \%$ and $50 \%$ methanol solutions at equilibrium and $25^{\circ} \mathrm{C}$ and $20 \%, 50 \%, 94 \%$ desorption of propranolol were obtained, respectively. Fig. 8 shows the result of desorption studies of propranolol after adding 50\% methanol solution at equilibrium with respect to solid loading. Around $94 \%$ desorption of propranolol was achieved using 50\% methanol solution when $14.47 \mathrm{mg}$ of solid adsorbent was added. 


\section{Conclusions}

In summary, silica and carboxymethyl- $\beta$-cyclodextrin functionalized $\mathrm{Fe}_{3} \mathrm{O}_{4}$ magnetic nanoparticles were synthesized and utilized for adsorptive removal of propranolol. Results from effect of $\mathrm{pH}$ study show that adsorption capacities of the particles increased as solution $\mathrm{pH}$ was increased and the behavior was dominated by hydrophobic interaction between propranolol and the nanoadsorbents. Adsorption capacities of as synthesized particles were compared to bare nanoparticles and it was found that the adsorption capacity was three times higher than that. All the adsorption equilibrium data were fitted well to Freundlich isotherm model thus showing heterogeneous adsorption. XPS spectroscopy were applied to investigate the adsorption mechanism and it was found that the hydrophobic portion of propranolol penetrated completely into the cyclodextrin cavity and amino group of propranolol interacted through hydrogen bond formation with the secondary hydroxyl group of cyclodextrin cavity. Finally, desorption studies show that the nanoadsorbents could be regenerated using methanol solution and using 50\% methanol solution almost complete regeneration of the adsorbent was achieved. Thus, the as-synthesized CMCD functionalized magnetic nanoparticles with all significant properties would have great potentials in adsorptive separation/ removal of beta-blocker

\section{References}

[1] T. V. Madureira, J.C. Barreiro, M. J. Rocha, E. Rocha, Q. B. Cass, M.E. Tiritan, Sci. Total Environ. 408 (2010) 5513.

[2] M. Maurer, B. Escher, P. Richile, C. Schaffner, A.
Alder, Water Res. $41 \quad$ (2007)

1614.

[3] M. Cleuvers, Chemosphere 59 (2005) 199.

[4] B. I. Escher, N. Bramaz, M. Richter, J. Lienert, Environ. Sci. Technol. 40 (2006) 7402.

[5] H. Ericson, G. Thorsén, L. Kumblad, Aquat. Toxicol. 99 (2010) 223.

[6] E. Giltrow, P.D. Eccles, M. J. Winter, P. J. McCormack, M. Rand-Weaver, T. H. Hutchinson, J. P. Sumpter, Aquat. Toxicol. 95 (2009) 195.

[7] E. Isarain-Chávez, R. M. Rodríguez, P. L. Cabot, F. Centellas, C. Arias, J. A. Garrido, E. Brillas, Water Res. 45 (2011) 4119.

[8] H. Wang, Y. -F. Yu, Q. -W. Chen, K. Cheng, Dalton Trans. 40 (2011) 559.

[9] X. Zhao, Y. Shi, Y. Cai, S. Mou, Environ. Sci. Technol. 42 (2008) 1201.

[10] F. H. Chen, Q. Gao, J. Z. Ni, Nanotechnology 19 (2008) 165103

[11] K. A. Connors, Chem. Rev. 97 (1997) 1325.

[12] Y. Deng, F. Wu, B. Liu, X. Hu, C. Sun, Chem. Eng. J. 174 (2011) 571.

[13] C. Gazpio, M. Sanchez, J. Isasi, I. Velaz, C. Martin, C. Martinez Oharriz, A. Zornoza, Carbohyd. Polym. 71 (2008) 140.

[14] H. Li, P. A. Helm, G. Paterson, C. D. Metcalfe, Chemosphere $\quad 83 \quad$ (2011) 271. [15] S. Ghosh, A. Z. M. Badruddoza, M.S. Uddin, K. Hidajat, J. Colloid Interface Sci. 354 (2011) 483.

[16] Y. Ji, X. Liu, M. Guan, C. Zhao, H. Huang, H. Zhang, C. Wang, J. Sep. Sci. 32 (2009) 2139.

[17] Y. -H. Lien, T. -M. Wu, J. Colloid Interface Sci. 326 (2008)

517.

[18] J. R. Domínguez, T. González, P. Palo, E. M. Cuerda-Correa, Desalination 269 (2011) 231.

[19] I. Langmuir, J. Am. Chem. Soc. 40 (1918) 1361.

[20] H. Freundlich, Phys. Chem. 57 (2011) 385. 